virtual consultations would be a further area to examine in relation to this.

Conflict of Interest None

\section{PRIMARY AND SECONDARY ICD IMPLANTATION IN ADULT CONGENITAL HEART DISEASE PATIENTS FROM 2006 TO 2020: A SINGLE CENTRE EXPERIENCE}

${ }^{1}$ Sally Hickman, ${ }^{2}$ Linda Birkitt, ${ }^{2}$ James Oliver, ${ }^{2}$ Kate English, ${ }^{3}$ Tom Slater, ${ }^{2}$ Anshuman Sengupta. ${ }^{1}$ Hull University Teaching Hospitals NHS Trust, Cottingham, UK; ${ }^{2}$ Leeds Teaching Hospitals NHS Trust; ${ }^{3}$ Sheffield Teaching Hospitals NHS Trust

\subsection{6/heartjnl-2021-BCS.24}

Introduction Adults with congenital heart disease are at risk of developing sustained ventricular arrhythmias, due to the underlying structural heart disease, myocardial scarring from previous cardiac surgery, or failing systemic or subpulmonary ventricles. Therefore, there are a number of potential indications for ICD implantation, both primary and secondary. Here we describe the rates of ICD implantation over the last 15 years in adults with congenital heart disease in our centre.

Methods A local database of all patients with congenital heart disease having undergone ICD implantation was interrogated to determine details of patients with new ICD implants from the last 15 years. Information on demographics, date of initial corrective cardiac surgery, date of ICD implant and indication for ICD were obtained.

Results 113 patients were identified, of which 65 (58\%) underwent primary prevention device implantation and 48 $(42 \%)$ underwent secondary prevention device implantation. 41 patients undergoing ICD insertion were female (36\%) and 72 were male (64\%).

An overall downtrend in numbers of ICDs being implanted per year over the last 15 years was seen (figure 1A), the fall in the last 5 years being especially pronounced (figure 1B). There was a minor increase in the proportion of ICDs implanted for primary prevention in 2015 to 2020 (63\%) compared to 2006 to 2015 (57\%).

Time between initial corrective surgery and ICD implantation was similar through 2006 to 2020. Between 2006 and 2015 the average number of years between surgery and ICD implant was 27 years for primary prevention and 23 years for secondary. In the last 5 years the average number of years

\begin{tabular}{lll}
\begin{tabular}{l} 
Abstract 24 Table 1 \\
Adults undergoing ICD implants in 'Other' \\
Category between 2006 and 2015 \\
\hline $2006-2015$
\end{tabular} & No of Pts & Primary or Secondary ICD \\
\hline Congenital Condition & 2 & Primary (1) \\
\hline Ebstein's & & Secondary (1) \\
AVSD & 2 & Primary (2) \\
Dextrocardia PS VSD ASD PDA & 1 & Secondary \\
PS & 2 & Secondary (2) \\
ASD & 2 & Secondary (2) \\
Anomalous coronary artery & 2 & Secondary (2) \\
Coarctation and bicuspid aortic valve & 1 & Primary \\
VSD & 3 & Primary (2) \\
& & Secondary (1) \\
\hline
\end{tabular}

Graph 1A

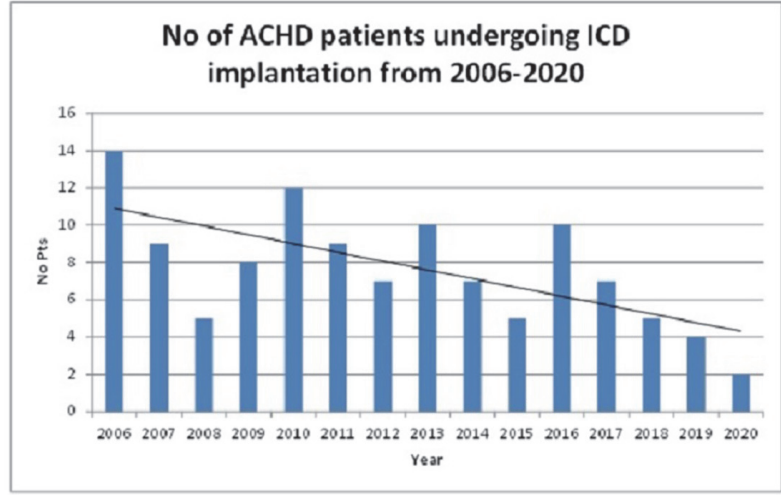

Graph 18

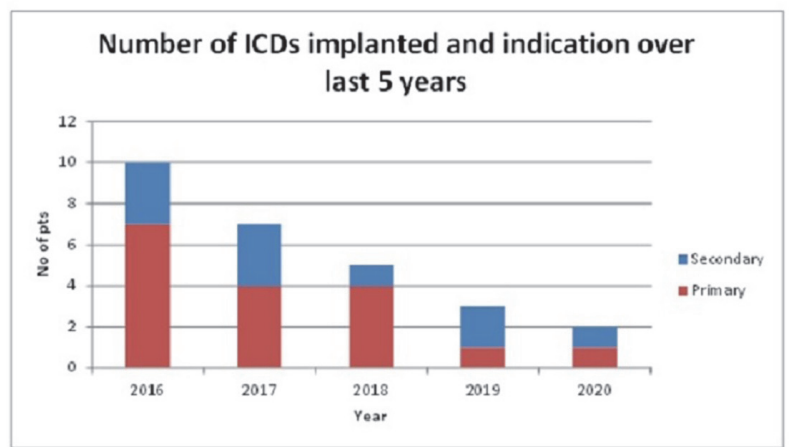

Abstract 24 Figure 1

Graph 2A

\section{Underlying Congenital Condition for all ICDs 2006-2015}

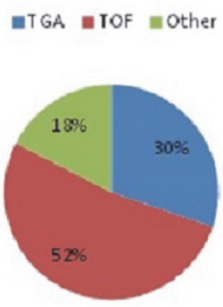

Graph 2B

\section{Underlying Congenital Condition for all ICDs 2016-2020}

-TGA $=$ TQF $\equiv$ Other

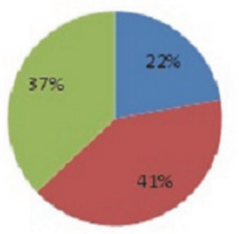


Abstract 24 Table 2 Adults undergoing ICD implants in 'Other' Category between 2016 and 2020

\begin{tabular}{lll}
\hline 2016-2020 & & \\
\hline Anomalous coronary artery & 2 & Secondary (2) \\
Pulmonary atresia, VSD, MAPCAs, central PA shunt & 1 & Primary \\
AVSD & 1 & Primary \\
VSD & 1 & Primary \\
Ebstein's & 2 & Primary (2) \\
PS & 1 & Primary \\
Double inlet LV, double outlet RV & 1 & Secondary \\
Coarctation and bicuspid aortic valve & 1 & Primary \\
\hline
\end{tabular}

between surgery and ICD implant was 23 years for both indications.

Figures $2 \mathrm{~A}$ and $2 \mathrm{~B}$ show the underlying condition in those who had an ICD implanted over the 15 year period. These demonstrate a decline in ICD implantation for those with either Tetralogy of Fallot or Transposition of the Great Arteries (TGA and CCTGA) in the last 5 years compared with data from $2006-2015 ; 52 \%$ to $41 \%$, and $30 \%$ to $22 \%$ respectively. The number of patients undergoing ICD implantation with 'Other' underlying congenital heart disease is shown to have increased from $18 \%$ of overall cases in 20062015 , to $37 \%$ of overall cases in 2016 to 2020 .

Tables 1 and 2 detail the 'Other' conditions and the indication for device.

Conclusions Despite the number of ACHD patients in the population increasing significantly over the same time period, annual rates of ICD implantation in our centre have reduced over time, especially over the last 5 years. The reason for this decline may reflect historical improvements in cardiac surgical techniques and the timing of surgery, thereby resulting in preserved ventricular function and less ventricular scar. Close, regular follow up in the modern era will likely result in early detection and treatment of structural problems which might be expected to reduce the incidence of serious arrhythmia. Regular surveillance would also be expected to allow for earlier detection of non-sustained ventricular arrhythmia, resulting in the initiation of anti-arrhythmic therapy that might prevent or delay the need for an ICD.

Conflict of Interest None

\section{ADVANCE CARE PLANNING IN PATIENTS WITH SYSTEMIC RIGHT VENTRICULAR FAILURE}

${ }^{1}$ Alice Copley, ${ }^{1}$ Sarah Gardner, ${ }^{1}$ Eleanor Joy, ${ }^{1} J a m e s$ Oliver, ${ }^{1}$ Kate English, ${ }^{2}$ Damien Cullington, 'Karina Gopaul. 'Leeds Teaching Hospitals NHS Trust, Leeds, UK; ${ }^{2}$ North West Congenital Cardiac Service

\subsection{6/heartjnl-2021-BCS.25}

Introduction Patients with transposition of the great arteries (ccTGA) and patients with transposition of the great arteries who had palliative surgery (Mustard/Senning procedures) often have progressive functional deterioration of the systemic right ventricle (sRV) and develop heart failure from the third or fourth decade of life. ${ }^{1}$ End stage heart failure requires an integrated approach and advance care planning (ACP) ${ }^{2}$ with ACHD cardiologists working alongside specialist heart failure and palliative care teams. We describe current practice with

regards to ACP and palliative care referrals in patients with sRV at a tertiary referral centre.

Methods Patients with ccTGA, Mustard or Senning procedures who were under active follow up from 2016 to 2021 were retrospectively analysed $(n=122)$. Clinical and echocardiographic data were extracted from hospital electronic records and screened for factors which should prompt the consideration of palliative care referral and ACP as specified in prior guidance. $^{2}$ These were; an episode of decompensation within 6 months despite optimal medical therapy, malignant arrhythmias, cardiac cachexia, frequent or continued intravenous therapies, poor quality of life (QoL), or progressive functional decline with dependence in activities of daily living and New York Heart Association (NYHA) IV symptoms.

Results Baseline information is summarised in table 1. 7 patients had ACP (figure 1). 2 occurred during hospital admission in NYHA III patients with more than 1 episode of decompensation in 6 months despite optimal medical therapy, need for frequent intravenous therapy and chronic poor QoL. Cardiopulmonary resuscitation, implanted cardiac defibrillator deactivation and future care preferences were discussed. 5 patients had ACP as an outpatient who were NYHA I or II, which were patient initiated $(n=3)$ and clinician initiated in response to progressive functional decline $(n=1)$ and no identifiable prompt $(n=1) .5$ patients died during the data collection period (median age 41 years), 1 of which had advanced heart failure, discussed ACP and was referred to palliative care. 2 patients did not have ACP or palliative care input, however did meet the criteria for doing so (table 2).

Abstract 25 Table 1 Baseline information and demographic data

\begin{tabular}{|l|l|}
\hline Age (mean \pm std dev) years & $39( \pm 9)$ \\
\hline CCTGA & $37(30.3 \%)$ \\
\hline Mustard procedure & $37(30.3 \%)$ \\
\hline Senning procedure & $48(39.3 \%)$ \\
\hline Presence of implanted cardiac defibrillator & $20(16.3 \%)$ \\
\hline 1 or more comorbidities* unrelated to ACHD diagnosis & $45(36.6 \%)$ \\
\hline Systemic RV function assessed by echocardiography \\
\hline Mildly impaired & $46(37.7 \%)$ \\
\hline Moderately impaired & $48(39.3 \%)$ \\
\hline Severely impaired & $17(13.9 \%)$ \\
\hline \\
-Major comorbidities involving a system, organ or multisystem disorder. "Visual assessment graded by \\
experienced congenital sonographers. Data was not available for 11 patients due to limited imaging.
\end{tabular}

experienced congenital sonographers. Data was not available for 11 patients due to limited imaging.

Abstract 25 Table 2 Patient features and factors meeting criteria for ACP or referral to palliative care in patients that died

\begin{tabular}{|l|l|l|l|l|l|}
\hline & $\begin{array}{l}\text { Cause or mode of } \\
\text { death }\end{array}$ & $\begin{array}{l}\text { Age of } \\
\text { death/ } \\
\text { years }\end{array}$ & $\begin{array}{l}\text { Advanced } \\
\text { heart failure" }\end{array}$ & $\begin{array}{l}\text { Had ACP or } \\
\text { palliative } \\
\text { care referrat? }\end{array}$ & $\begin{array}{l}\text { Factors meeting criteria for ACP or } \\
\text { referral to palliative care }\end{array}$ \\
\hline 1 & $\begin{array}{l}\text { Cardiac arrest, } \\
\text { arrhythmia" }\end{array}$ & 73 & No & No & $\begin{array}{l}\text { Recurrent atrial arrhythmias } \\
\text { NYHA II }\end{array}$ \\
\hline 2 & $\begin{array}{l}\text { End stage heart } \\
\text { failure }\end{array}$ & 53 & Yes & Yes & $\begin{array}{l}\text { Recurrent hospital admissions } \\
\text { requiring IV treatment } \\
\text { Progressive functional decline and } \\
\text { QoL } \\
\text { Dependence in activities of daily } \\
\text { living } \\
\text { NYHA IV }\end{array}$ \\
\hline 3 & $\begin{array}{l}\text { Cerebrovascular } \\
\text { event }\end{array}$ & 41 & $\begin{array}{l}\text { Yes - } \\
\text { ventricular } \\
\text { assist device }\end{array}$ & No & $\begin{array}{l}\text { IV diuretic therapy frequency } \\
\text { increased } \\
\text { Progressive functional decline and } \\
\text { QoL pre MCS } \\
\text { NYHA III }\end{array}$ \\
\hline 4 & Cardiac arrest"* & 38 & No & No & $\begin{array}{l}\text { Progressive functional decline, } \\
\text { NYHA III }\end{array}$ \\
\hline 5 & $\begin{array}{l}\text { Acute } \\
\text { decompensated } \\
\text { heart failure }\end{array}$ & 28 & No & No & $\begin{array}{l}\text { Frequent admissions with } \\
\text { decompensated HF requiring } \\
\text { intravenous diuretics } \\
\text { Progressive functional decline and } \\
\text { QoL limiting daily activities } \\
\text { NYHA III }\end{array}$ \\
\hline
\end{tabular}

